\title{
COVID-19 ASSOCIATED COAGULOPATHY AND IMPLICATIONS FOR ITS TREATMENT
}

\author{
Zh. Cherneva' ${ }^{1}$, R. Cherneva ${ }^{2}$ \\ ${ }^{1}$ University Hospital of the Ministry of Internal Affairs - Sofia, Bulgaria \\ ¿University Hospital for Respiratory Diseases "Sv. Sophia" - Sofia, Bulgaria
}

\begin{abstract}
The SARS-CoV-2 coronavirus (COVID-19) pandemic is due to lack of prior immunity and there is no certain management, regarding the complications of this viral illness. The target organ for COVID-19 infection are the lungs. Patients may develop acute lung injury that can be complicated by acute respiratory failure, as well as multiorgan failure. The pathophysiology of COVID-19 infection is characterized with inflammatory changes, as sociated with coagulopathy. Recent data suggests diffuse bilateral pulmonary inflammation observed in COVID-19 infection that is related to a novel pulmonary-specific vasculopathy, defined as pulmonary intravascular coagulopathy (PIC), distinct from disseminated intravascular coagulopathy (DIC). The coagulopathy associated with COVID-19 is distinguished by initial elevation of D-dimer and fibrin/fibrinogen degradation products. Abnormalities in prothrombin time (PT), partial thromboplastin time (APTT) and platelet counts are not common in the early stages of the infection. This suggests the early screening measurement of D-dimer and fibrinogen. The implications for COVID-19-associated-coagulopathy is the established thromboembolic prophylaxis and standard management for sepsis-induced coagulopathy or DIC. High levels of D-dimer are a marker of higher mortality risk. However, current studies do not show the common use of full therapeutical doses of anticoagulants, unless there are other clinical indications. Bleeding in COVID-19 infection is uncommon, even when a laboratory constellation for DIC is present. However, if it occurs, standard guidelines for DIC management should be followed.
\end{abstract}

Key words: coagulopathy, coronavirus, COVID-19, anticoagulation, sepsis

Corresponding author: Zheyna Vlaeva Cherneva, University Hospital of the Ministry of Internal Affairs, 79 "General Skobelev" Blvd., 1606 Sofia, Bulgaria, e-mail: jenicherneva@yahoo.com

\section{INTRODUCTION}

T he pandemic of SARS-CoV-2 is a human infection, defined by the World Health Organization as Coronavirus Disease 2019 (COVID-19), characterized with high morbidity and mortality. Bats and birds serve as the typical coronavirus hosts with zoonotic spread and animal-animal-human transmission [1]. In December 2019, an outbreak of a novel member of the coronavirus was noted, similar with other SARS viruses, where bats are the viral reservoir [2].

SARS-CoV-2 is like Severe Acute Respiratory Syndrome (SARS) and Middle East Respiratory Syndrome (MERS) viruses that belong to the Coronaviridae family. These RNA-viruses have an envelope of glycoproteins with the characteristic of a corona on electron microscopic imaging. It consists of spike-proteins, or $S$ proteins, responsible for the tropism with specific angiotensin-converting enzyme 2 (ACE2) re- 
ceptors on the surface of respiratory epithelium and endothelial vascular cells [3-5].

The aim of this review is to discuss the coagulopathy associated with COVID-19 and the different strategies of its therapeutical management.

\section{DEFINITIONS FOR COVID-19-ASSOCIATED COAGULOPATHY}

Microorganisms and their components, binding to specific receptors, induce the expression of tissuefactor from monocytes and macrophages and activation of immune cells [6-10]. This results in increased levels of proinflammatory cytokines that have pleiotropic effects, including activation of coagulation, that can progress to consumptive coagulopathy. The International Society of Thrombosis and Haemostasis (ISTH) has implicated diagnostic criteria for DIC, as well as for sepsis-induced coagulopathy (SIC) [1113]. SIC occurs earlier and is less severe than DIC and with the progression of sepsis can develop into DIC [12-14].

In Chinese patients with COVID-19 both ISTH definitions of DIC and SIC have been used. Whether COVID-19 associated coagulopathy linearly progresses to SIC and then to DIC is still elusive. Accurate treatment implications may prevent this, as well as the later development of SIC or DIC $[15,16]$.

The acronym COVID-19-associated coagulopathy (CAC) describes a novel pulmonary-specific vasculopathy, defined as pulmonary intravascular coagulopathy (PIC), that is distinct from DIC. Although more data is necessary, SARS-CoV-2 virus does not seem to have procoagulant effects itself. Coagulation abnormalities seen in SARS-CoV-2 infected patients are more likely due to the profound inflammatory processes. The "COVID-19-associated coagulopathy" develops early in the course of the disease as abnormalities in coagulation tests are seen early. However, it does not coincide with the usual definition of a clinical coagulopathy, where there is impaired formation of clots and consequent bleeding [16-21].

\section{COVID-19-ASSOCIATED COAGULOPATHY - DATA FROM WUHAN}

Early reports from China show abnormal coagulation in COVID-19 patients. In group of 99 patients, hospitalized in Wuhan, $6 \%$ had an elevated aPTT, 5\% - elevated PT, 36\% - elevated D-dimer, increased interleukin-6 (IL-6), erythrocyte sedimentation rate (ESR), and C-reactive protein (CRP). Only $12 \%$ of the patients had thrombocytopenia [17].
Another Wuhan hospital reported 138 patients with minimal elevations in PT and normal aPTT. Of the ICU patients, $26 \%$ had higher D-dimer levels 5 days after onset of symptoms [18].

A study of 191 patients from 2 main Wuhan hospitals showed $28 \%$ (54-patients) mortality. It was associated with high D-dimer $>1.0 \mathrm{mcg} / \mathrm{mL}$ on admission, increased PT, elevations in IL-6, troponin levels. All of the non-survivors were with sepsis, and $50 \%$ had coagulopathy, however, DIC was not assessed [19].

In another publication, the investigators evaluated 1099 COVID-19 patients, that required hospitalization and 173 of them were with severe pneumonia at admission, based on the American Thoracic Society criteria. Forty three $(25 \%)$ of these individuals experienced a primary outcome (ICU admission, ventilator support or death), compared to $3.6 \%$ in the non-severe group. D-dimer values $>0.5 \mathrm{mg} /$ liter was associated with severe disease, experiencing a primary outcome $[20,21]$.

\section{INFLAMMATION AND COAGULATION IN COVID-19 INFECTION}

Infection due to viral, bacterial, or fungal pathogens activates complex systemic inflammatory processes, that are a part of innate immunity. Coagulation is triggered by the inflammatory response through several pathways. Polyphosphates, originated from microorganisms, stimulate platelets, mast cells, and FXII, amplifying the procoagulant response of the intrinsic coagulation [22-25]. The complement also contributes to activation of coagulation factors [26, 27]. Pathogen-associated molecular mechanisms (PAMPs) help for the interactions between the immune response and coagulation [10, 28]. The inflammatory effects of cytokines result in endothelial injury with prothrombotic properties [10, 29].

Circulating serine protease inhibitors - antithrombin, $C 1$ esterase inhibitor, and protein $C$ are decreased by the inflammatory response to infection [30, 31]. Vascular endothelial injury may induce further thrombocytopenia, a decrease of natural anticoagulants and progression to thrombotic DIC [32-34].

Significant inflammation is present in patients with COVID-19 infection - elevated levels of IL-6, increased CRP and elevated fibrinogen [35]. The virus tropism for ACE2 receptors results in endothelial cell damage and impairment of the natural antithrombotic state. Subsequent activation of coagulation is the probable cause for the elevated D-dimer levels, as increased levels have been associated with many conditions other than thromboembolism [36-38]. 
Some patients have a more profound inflammatory response to infection with SARS-CoV2 - systemic inflammatory response syndrome (SIRS) or cytokine storm. It leads to changes in coagulation tests and significantly elevated D-dimer, especially as the disease progresses [39]. Tang et al, showed that fibrinogen levels were elevated in all patients on admission [15]. Ranucci et al, demonstrated increased levels of fibrinogen, D-dimer, IL-6 levels in COVID-19 patients with acute respiratory disstress syndrome (ARDS), requiring mechanical ventilation. Elevated IL-6 levels correlated with increased fibrinogen levels, confirming the link between inflammation and procoagulant changes [40].

\section{ENDOTHELIALOPATHY AND COVID-19}

In SARS-CoV-2 infection, except for endothelial dysfunction, associated with sepsis-induced-coagulopathy, there are local microcirculatory changes, related to endothelitis [29, 41]. The Angiotensin-converting enzyme (ACE) 2 receptor on endothelial cells allows for viral replication and inflammatory response, resulting in endothelial cell apoptosis and microvascular prothrombotic effects [42]. Recent data confirms the presence of viral inclusions within endothelial cells, mononuclear and polymorphonuclear cellular infiltration, as well as endothelial apoptosis in post mortem histology of SARS-CoV-2 infection [43].

\section{MANAGEMENT OF COVID-19-ASSOCIATED COAGULOPATHY}

\section{Coagulation Test}

COVID-19 patients should have coagulation testing on admission - D-dimer, PT, aPTT, fibrinogen, and platelet count. The rising D-dimer in non-survivors and the rapid drop in fibrinogen associated with DIC is seen between 7-11 days after onset of symptoms. Elevation of D-dimer, PT, and aPTT, the decrease of fibrinogen and platelet count starts between 7-10 days after admission, although increased D-dimer can start at the fourth day $[15,18,19]$.

\section{Venous thromboembolism (VTE) prophylaxis}

Although the frequency of VTE is low in the Asian population, Tang et al, reported $22 \%$ of the patients received prophylactic dose low-molecular weight heparin (LMWH) or unfractionated heparin (UFH) [16]. In COVID-19 patients microvascular thrombosis and pulmonary emboli were reported [44-47]. Early autopsy demonstrated microvascular thrombosis, as well as marked inflammatory changes [48]. In patients with severe COVID-19 at presentation and
SIC score of $>4$ or D-dimer $>6 \times$ upper limit of normal, prophylactic doses of enoxaparin or UFH have decreased mortality $[49,50]$. Many centers have increased the dose of anticoagulation for prophylaxis to "intermediate intensity": UFH 7,500 units three times daily or enoxaparin $40 \mathrm{mg}$ twice daily. The increase of the doses were based on levels of D-dimer, fibrinogen, ICU location, or other factors, associated with increased risk [51, 52].

\section{Microvascular Thrombosis: Treatment}

Patients with COVID-19 associated coagulopathy may not develop SIC, DIC or a bleeding diathesis. Although anticoagulants mitigate microvascular thrombosis and possibly end-organ dysfunction, no survival advantages have been found in prior trials in patients with sepsis. Patients with sepsis alone or sepsis and SIC or overt DIC should continue to receive prophylactic anticoagulation as previously discussed [53].

\section{Microvascular Thrombosis: Prevention}

Full-dose anticoagulation has been considered in COVID-19 patients for preventing microvascular thrombosis during severe infection. Infection can result in the development of ARDS, where fibrin-platelet microthrombi are seen in the pulmonary microcirculation and parenchyma, a syndrome consistent with thrombotic DIC. However, data does not support full dose anticoagulation at this time for this indication. Prior studies using anticoagulants in DIC have found no decrease in mortality [54, 55]. Previous investigations demonstrated that heparin in-vitro reduced the coronavirus SARS-CoV infectivity by $50 \%$ [56]. Whether this is due to inhibition of cleavage of the $S$ protein by coagulation factor Xa which allows cell entry or it is due to heparin blocking the charged spike protein from binding its host cell receptor, is elusive $[57,58]$. There is no data that heparin decreases infectivity of SARS-CoV-2.

\section{Clinical indications for therapeutic anticoagulation}

COVID-19 patients, especially those that are critically ill, should be treated with LMWH or UFH instead of a direct oral anticoagulant. In patients with other indications for anticoagulation (VTE, atrial fibrillation, mechanical cardiac valves), anticoagulants should be continued at full dose. The question of using therapeutic dose anticoagulation for presumed pulmonary emboli (PE) has been hindered due to mechanical ventilation of critically ill patients and disability to move them to CT scanners. D-dimer levels are usually elevated at admission and are not helpful for considering therapeutical behavior. Sudden respiratory decompensation, right heart strain on echocar- 
diography, or deep venous thromboemblosim (DVT), seen on lower extremity ultrasound, are indications for full therapeutical dose anticoagulation [59-61].

\section{CONCLUSION}

The COVID-19 pandemic is due to a pathogen, whose behavior continues to be defined, so that to optimize treatment, improve clinical outcome and reduce mortality. Data from Wuhan, USA, Netherlands, France suggest different strategies for the management of coagulopathy associated with COVID-19.

It is more profound in those, presenting with severe disease symptoms, that develop pulmonary intravascular coagulopathy (PIC). COVID-19-associated coagulopathy should be treated following the standard practice of VTE prophylaxis for critically ill patients, SIC or DIC. Although high levels of D-dimer are associated with mortality, only few studies suggest full therapeutical dose anticoagulation.

This review confirms the role of coagulopathy for COVID-19 infection and the need for its optimal therapeutic management.

Disclosure summary: The authors have nothing to disclose.

\section{REFERENCES:}

1. Layton DS, Choudhary A, Bean AGD. Breaking the chain of zoonoses through biosecurity in livestock. Vaccine 2017;35:5967-73.

2. Wu F, Zhao S, Yu B, et al. A new coronavirus associated with human respiratory disease in China. Nature 2020;579:265-9.

3. Hulswit RJ, de Haan CA, Bosch BJ. Coronavirus Spike Protein and Tropism Changes. Adv Virus Res 2016;96:29-57.

4. Lu R, Zhao X, Li J, et al. Genomic characterisation and epidemiology of 2019 novel coronavirus: implications for virus origins and receptor binding. Lancet 2020;395:565-74.

5. Schnittler HJ, Feldmann H. Viral hemorrhagic fever - a vascular disease? Thromb Haemost 2003;89:967-72.

6. Iba T, Levy JH, Thachil J, et al. The progression from coagulopathy to disseminated intravascular coagulation in representative underlying diseases. Thromb Res 2019;179:11-4.

7. Iba T, Levy $\mathrm{JH}$, Wada $\mathrm{H}$, et al. Differential diagnoses for sepsis-induced disseminated intravascular coagulation: communication from the SSC of the ISTH. J Thromb Haemost 2019;17:415-9.

8. Woei AJFJ, van der Starre WE, Tesselaar ME, et al. Procoagulant tissue factor activity on microparticles is associated with disease severity and bacteremia in febrile urinary tract infections. Thromb Res 2014;133:799-803.

9. Gould TJ, Lysov Z, Swystun LL, et al. Extracellular Histones Increase Tissue Factor Activity and Enhance Thrombin Generation by Human Blood Monocytes. Shock 2016;46:65562.
10. Iba T, Levy JH. Inflammation and thrombosis: roles of neutrophils, platelets and endothelial cells and their interactions in thrombus formation during sepsis. J Thromb Haemost 2018;16:231-41.

11. Suzuki K, Wada $\mathrm{H}$, Imai $\mathrm{H}$, et al. A re-evaluation of the Ddimer cut-off value for making a diagnosis according to the ISTH overt-DIC diagnostic criteria: communication from the SSC of the ISTH. J Thromb Haemost 2018;16:1442-4.

12. Iba T, Levy JH, Warkentin TE, et al. Diagnosis and management of sepsis-induced coagulopathy and disseminated intravascular coagulation. J Thromb Haemost 2019.

13. Taylor FB, Jr., Toh CH, Hoots WK, Wada H, Levi M. Towards definition, clinical and laboratory criteria, and a scoring system for disseminated intravascular coagulation. Thromb Haemost 2001;86:1327-30.

14. Iba T, Levy JH, Yamakawa K, et al. Proposal of a two-step process for the diagnosis of sepsis-induced disseminated intravascular coagulation. J Thromb Haemost 2019;17:1265-8.

15. Tang N, Li D, Wang X, Sun Z. Abnormal coagulation parameters are associated with poor prognosis in patients with novel coronavirus pneumonia. J Thromb Haemost 2020.

16. Tang N, Bai H, Chen X, Gong J, Li D, Sun Z. Anticoagulant treatment is associated with decreased mortality in severe coronavirus disease 2019 patients with coagulopathy. J Thromb Haemost 2020.

17. Chen N, Zhou M, Dong X, et al. Epidemiological and clinical characteristics of 99 cases of 2019 novel coronavirus pneumonia in Wuhan, China: a descriptive study. Lancet 2020;395:507-13.

18. Wang D, Hu B, Hu C, et al. Clinical Characteristics of 138 Hospitalized Patients With 2019 Novel Coronavirus-Infected Pneumonia in Wuhan, China. JAMA 2020.

19. Zhou F, Yu T, Du R, et al. Clinical course and risk factors for mortality of adult inpatients with COVID-19 in Wuhan, China: a retrospective cohort study. Lancet 2020;395:1054-62.

20. Guan WJ, Ni ZY, Hu Y, et al. Clinical Characteristics of Coronavirus Disease 2019 in China. N Engl J Med 2020.

21. Metlay JP, Waterer GW, Long AC, et al. Diagnosis and Treatment of Adults with Community-acquired Pneumonia. An Official Clinical Practice Guideline of the American Thoracic Society and Infectious Diseases Society of America. Am J Respir Crit Care Med 2019;200:e45-e67.

22. Engelmann B, Massberg S. Thrombosis as an intravascular effector of innate immunity. Nat Rev Immunol 2013;13:34-45.

23. Delabranche X, Helms J, Meziani F. Immunohaemostasis: a new view on haemostasis during sepsis. Annals of intensive care 2017;7:117.

24. Jackson SP, Darbousset R, Schoenwaelder SM. Thromboinflammation: challenges of therapeutically targeting coagulation and other host defense mechanisms. Blood 2019;133:90618.

25. Smith SA, Mutch NJ, Baskar D et al. Polyphosphate modulates blood coagulation and fibrinolysis. Proc Natl Acad Sci U S A 2006;103:903-8.

26. Subramaniam S, Jurk K, Hobohm L, et al. Distinct contributions of complement factors to platelet activation and fibrin formation in venous thrombus development. Blood 2017;129:2291-302.

27. Noubouossie DF, Reeves BN, Strahl BD, Key NS. Neutrophils: back in the thrombosis spotlight. Blood 2019;133:2186-97.

28. Rittirsch D, Flierl MA, Ward PA. Harmful molecular mechanisms in sepsis. Nat Rev Immunol 2008;8:776-87.

29. Iba T, Levy JH. Derangement of the endothelial glycocalyx in sepsis. J Thromb Haemost 2019;17:283-94. 
30. Semeraro F, Colucci M, Caironi P, et al. Platelet Drop and Fibrinolytic Shutdown in Patients With Sepsis. Crit Care Med 2018;46:e221-e8.

31. Levy JH, Koster A, Quinones QJ, Milling TJ, Key NS. Antifibrinolytic Therapy and Perioperative Considerations. Anesthesiology 2018;128:657-70.

32. Iba T, Arakawa M, Ohchi $\mathrm{Y}$, et al. Prediction of Early Death in Patients With SepsisAssociated Coagulation Disorder Treated With Antithrombin Supplementation. Clin Appl Thromb Hemost 2018:1076029618797474.

33. Kienast J, Juers M, Wiedermann CJ, et al. Treatment effects of high-dose antithrombin without concomitant heparin in patients with severe sepsis with or without disseminated intravascular coagulation. J Thromb Haemost 2006;4:90-7.

34. Yamakawa K, Levy JH, Iba T. Recombinant human soluble thrombomodulin in patients with sepsis-associated coagulopathy (SCARLET): an updated meta-analysis. Crit Care 2019;23:302.

35. Chen G, Wu D, Guo W, et al. Clinical and immunologic features in severe and moderate Coronavirus Disease 2019. J Clin Invest 2020.

36. Huang C, Wang Y, Li X, et al. Clinical features of patients infected with 2019 novel coronavirus in Wuhan, China. Lancet 2020;395:497-506.

37. Levi M, Scully M. How I treat disseminated intravascular coagulation. Blood 2018;131:845-54.

38. Lippi G, Bonfanti L, Saccenti C, Cervellin G. Causes of elevated D-dimer in patients admitted to a large urban emergency department. Eur J Intern Med 2014;25:45-8.

39. Mehta P, McAuley DF, Brown M, et al. COVID-19: consider cytokine storm syndromes and immunosuppression. Lancet 2020;395:1033-4.

40. Ranucci M, Ballotta A, Di Dedda U, et al. The procoagulant pattern of patients with COVID-19 acute respiratory distress syndrome. J Thromb Haemost 2020.

41. Saffarzadeh M, Juenemann C, Queisser MA, et al. Neutrophil extracellular traps directly induce epithelial and endothelial cell death: a predominant role of histones. PLoS One 2012; 7:e32366.

42. Ferrario CM, Jessup J, Chappell MC, et al. Effect of angiotensin-converting enzyme inhibition and angiotensin II receptor blockers on cardiac angiotensin-converting enzyme 2. Circulation 2005;111:2605-10.

43. Varga Z, Flammer AJ, Steiger P, et al. Endothelial cell infection and endotheliitis in COVID-19. Lancet 2020.

44. Stein PD, Kayali F, Olson RE, Milford CE. Pulmonary thromboembolism in Asians/Pacific Islanders in the United States: analysis of data from the National Hospital Discharge Survey and the United States Bureau of the Census. Am J Med 2004;116:435-42.

45. Zakai NA, McClure LA. Racial differences in venous thromboembolism. J Thromb Haemost 2011;9:1877-82.

46. Danzi GB, Loffi M, Galeazzi G, Gherbesi E. Acute pulmonary embolism and COVID-19 pneumonia: a random association? European Heart Journal 2020.
47. Xie Y, Wang X, Yang P, Zhang S. COVID-19 Complicated by Acute Pulmonary Embolism. Radiology: Cardiothoracic Imaging 2020;2:e200067.

48. Tian S, Hu W, Niu L, Liu H, Xu H, Xiao S-Y. Pulmonary Pathology of Early-Phase 2019 Novel Coronavirus (COVID-19) Pneumonia in Two Patients With Lung Cancer. Journal of Thoracic Oncology.

49. Klok FA, Kruip M, van der Meer NJM, et al. Incidence of thrombotic complications in critically ill ICU patients with COVID-19. Thromb Res 2020.

50. Poissy J, Goutay J, Caplan M, et al. Pulmonary Embolism in COVID-19 Patients: Awareness of an Increased Prevalence. Circulation 2020.

51. Pannucci CJ, Fleming KI, Holoyda K, Moulton L, Prazak AM, Varghese TK, Jr. Enoxaparin $40 \mathrm{mg}$ per Day Is Inadequate for Venous Thromboembolism Prophylaxis After Thoracic Surgical Procedure. Ann Thorac Surg 2018;106:404-11.

52. Wang TF, Milligan PE, Wong CA, Deal EN, Thoelke MS, Gage BF. Efficacy and safety of high-dose thromboprophylaxis in morbidly obese inpatients. Thromb Haemost 2014;111:8893.

53. Wada $\mathrm{H}$, Thachil J, Di Nisio M, et al. Guidance for diagnosis and treatment of DIC from harmonization of the recommendations from three guidelines. J Thromb Haemost 2013.

54. Lin L, Lu L, Cao W, Li T. Hypothesis for potential pathogenesis of SARS-CoV-2 infection-a review of immune changes in patients with viral pneumonia. Emerg Microbes Infect 2020;9:727-32

55. Iba T, Levy JH, Raj A, Warkentin TE. Advance in the Management of Sepsis-Induced Coagulopathy and Disseminated Intravascular Coagulation. J Clin Med 2019;8.

56. Vicenzi E, Canducci F, Pinna D, et al. Coronaviridae and SARS-associated coronavirus strain HSR1. Emerg Infect Dis 2004;10:413-8.

57. Du L, Kao RY, Zhou Y, et al. Cleavage of spike protein of SARS coronavirus by protease factor $\mathrm{Xa}$ is associated with viral infectivity. Biochem Biophys Res Commun 2007;359:174-9.

58. Kam YW, Okumura $\mathrm{Y}$, Kido $\mathrm{H}$ et al. Cleavage of the SARS coronavirus spike glycoprotein by airway proteases enhances virus entry into human bronchial epithelial cells in vitro. PLoS One 2009;4:e7870.

59. Smyth SS, McEver RP, Weyrich AS, et al. Platelet functions beyond hemostasis. J Thromb Haemost 2009;7:1759-66.

60. Levy JH, Goodnough LT. How I use fibrinogen replacement therapy in acquired bleeding. Blood 2015;125:1387-93.

61. Thachil J, Tang N, Gando S, et al. ISTH interim guidance on recognition and management of coagulopathy in COVID-19. J Thromb Haem, 2020.

Received: 14 May 2020, Accepted: 16 June 2020, Last revised: 11 August 2020 